\title{
Continued Functioning of the Secretory Pathway Is Essential for Ribosome Synthesis
}

\author{
KEIKO MIZUTA† AND JONATHAN R. WARNER* \\ Department of Cell Biology, Albert Einstein College of Medicine, Bronx, New York 10461
}

Received 27 September 1993/Returned for modification 23 November 1993/Accepted 5 January 1994

\begin{abstract}
To explore the regulatory elements that maintain the balanced synthesis of the components of the ribosome, we isolated a temperature-sensitive ( $t s)$ mutant of Saccharomyces cerevisiae in which transcription both of rRNA and of ribosomal protein genes is defective at the nonpermissive temperature. Temperature sensitivity for growth is recessive and segregates 2:2. A gene that complements the $t s$ phenotype was cloned from a genomic DNA library. Sequence analysis revealed that this gene is $S L Y 1$, encoding a protein essential for protein and vesicle transport between the endoplasmic reticulum and the Golgi apparatus. In the strain carrying our $t s$ allele of $S L Y 1$, accumulation of the carboxypeptidase $Y$ precursor was detected at the nonpermissive temperature, indicating that the secretory pathway is defective. To ask whether the effect of the $t s$ allele on ribosome synthesis was specific for sly1 or was a general result of the inactivation of the secretion pathway, we assayed the levels of mRNA for several ribosomal proteins in cells carrying ts alleles of $\sec 1, \sec 7, \sec 11, \sec 14$, sec18, sec53, or sec63, representing all stages of secretion. In each case, the mRNA levels were severely depressed, suggesting that this is a common feature in mutants of protein secretion. For the mutants tested, transcription of rRNA was also substantially reduced. Furthermore, treatment of a sensitive strain with brefeldin $A$ at a concentration sufficient to block the secretion pathway also led to a decrease of the level of ribosomal protein mRNA, with kinetics suggesting that the effect of a secretion defect is manifest within 15 to $30 \mathrm{~min}$. We conclude that the continued function of the entire secretion pathway is essential for the maintenance of ribosome synthesis. The apparent coupling of membrane synthesis and ribosome synthesis suggests the existence of a regulatory network that connects the production of the various structural elements of the cell.
\end{abstract}

Cell growth requires regulation on several levels. On the one hand there is the regulation of the DNA cycle, the entry into $S$ phase, the doubling of the genetic material, and its equal distribution into two daughter cells. On the other hand there is also doubling of the other components of the cell, including soluble proteins, membranes of various sorts, and ribosomes. While this is generally not coupled rigidly to the cell cycle, the cell must maintain some balance between the levels of these various components in order to ensure optimal growth. Certain components, e.g., the ribosomes, are also subject to regulation in response to environmental conditions.

Indeed, some of the earliest work on the biochemistry of growth regulation showed that in Escherichia coli ribosome synthesis is intimately associated with growth rate (reviewed in reference 20). In Saccharomyces cerevisiae, the ribosome content of the cell is dependent on the growth rate (42). Upon a shift from a poor to a good carbon source, there is an immediate increase in the transcription of rRNA and ribosomal protein mRNA that precedes the increase in growth rate (15). During a growth cycle, ribosome synthesis occurs at a high level during early log phase but declines rapidly once the cells have reached about $30 \%$ of their final density and ceases almost entirely by the time the cells have reached $50 \%$ of their final density (14). In each of these systems, the ribosome synthesis has proved to be a sensitive barometer of the future behavior of the cell.

\footnotetext{
* Corresponding author. Mailing address: Department of Cell Biology, Albert Einstein College of Medicine of Yeshiva University, 1300 Morris Park Ave., Bronx, NY 10461. Phone: (718) 430-3022. Fax: (718) 829-7619.

$\dagger$ Present address: Department of Biochemistry and Biophysics, Research Institute for Nuclear Medicine and Biology, Hiroshima University, Minami-ku, Hiroshima 734, Japan.
}

Ribosome synthesis depends on three types of transcription, by three different RNA polymerases (Pols): transcription of rRNA genes by PolI, transcription of 5S RNA genes by PolIII, and transcription of ribosomal protein genes by PolII. What are the signals to which the cell responds in order to regulate ribosome synthesis? Is ribosome synthesis affected by aspects of cell growth other than the metabolism of small molecules? Is there regulation of a primary component that in turn controls the others, or is there a parallel regulation of the transcription of the components of the ribosome? To approach these questions we have searched for temperature-sensitive (ts) mutants deficient in the transcription of ribosomal protein mRNA with the goal of detecting genes involved in the fundamental regulation of ribosome synthesis. Unexpectedly, we found that a mutation in the $S L Y 1$ gene, whose product plays a role in the transfer of membrane material from the endoplasmic reticulum (ER) to the Golgi apparatus $(4,28)$, had a drastic effect on transcription of both rRNA and ribosomal protein genes. Further experiments revealed that the functioning of the entire secretory pathway is necessary for the continued synthesis of ribosomes. The apparent coupling of membrane synthesis and ribosome synthesis suggests the existence of a regulatory network that connects the synthesis of the various structural elements of the cell.

\section{MATERIALS AND METHODS}

Strains, plasmids, and growth conditions. The $S$. cerevisiae strains used in this study are listed in Table 1 . Yeast cells were grown in either yeast extract-peptone-dextrose (YPD) or minimal medium supplemented with $2 \%$ glucose as a carbon source. A library consisting of partial Sau3A fragments of $S$. cerevisiae genomic DNA inserted into the vector YCp50 was generously provided by M. D. Rose (33). 
TABLE 1 . Yeast strains used in this study

\begin{tabular}{|c|c|c|}
\hline Strain & Genotype & Source \\
\hline J1003.1D & $\begin{array}{l}\text { MAT } \alpha \text { trp1 ade2-1 ura3-1 leu2-3,112 } \\
\text { can1-100 }\end{array}$ & This study \\
\hline $\mathrm{J} 1003.1 \mathrm{E}$ & $\begin{array}{l}\text { MATa his3-111 ade2-1 ura3-1 leu2-3,112 } \\
\quad \text { can1-100 }\end{array}$ & This study \\
\hline 312 & $\begin{array}{l}\text { MAT } \alpha \text { trp1 ade2-1 ura3-1 leu2-3,112 } \\
\text { can1-100 sly1 }\end{array}$ & This study \\
\hline $\mathrm{J} 250$ & $M A T \alpha$ ural tyr1 his 7 pep 4 & B. Jones \\
\hline NY3 & MATa ura3-52 $\sec 1-1$ & P. Novick \\
\hline NY430 & $M A T \mathbf{a}$ ura3-52 $\mathrm{sec} 14-3$ & P. Novick \\
\hline NY431 & MAT a ura3-52 $\sec 18-1$ & P. Novick \\
\hline NY760 & $M A T \alpha$ ura3-52 sec7-1 & P. Novick \\
\hline RSY12 & MAT $\alpha$ ura3-52 leu2-3,112 sec53-6 & R. Schekman \\
\hline RSY151 & MAT $\alpha$ ura3-52 leu2-3,112 рер4-3 sec63-1 & R. Schekman \\
\hline R757 & MAT $\alpha$ ura3-52 his4-15 lys 9 & R. F. Gaber \\
\hline MD59 & $M A T \alpha$ ura3-52 his4-15 lys9 erg6 $\Delta$ & R. F. Gaber \\
\hline
\end{tabular}

Northern blot analysis. Northern (RNA) blot analysis was carried out with $1.5 \%$ agarose gels in formaldehyde and Nytran membranes as described previously (7). ${ }^{32} \mathrm{P}$-labeled antisense RNAs were used as probes for TCM1 (encoding ribosomal protein L3), RPL32, RPS10, $A C T 1$, and $P Y K 1 .{ }^{32} \mathrm{P}$-labeled DNA probes specific for $Y L 8, R P A O, R P L 44$, and $T E F 1$ were prepared by the method of random primer extension of a fragment comprising the coding region of the gene. ${ }^{32} \mathrm{P}$-labeled oligonucleotide probes for TCM1, CYH2 (encoding ribosomal protein L29), RPL32, $A C T 1, E N O 1$, and U3 RNA were prepared by using polynucleotide kinase. U3 RNA is a convenient marker to correct for unequal loading. It is abundant and stable and therefore little affected by metabolic changes in the cell. It is small enough (335 nucleotides) to migrate ahead of most mRNAs.

Construction of plasmids. An isolated clone that complements the temperature sensitivity of mutant 312 was digested with BamHI or HindIII, and the fragments were subcloned into YCp50. Deletions within the 7-kb HindIII fragment were constructed by digestion with exonuclease III and mung bean nuclease or by digestion with SpeI and religation (see Fig. 4). For the integration of $S L Y 1$ into the mutant cells, a SacI$H$ indIII fragment containing $S L Y 1$ was inserted into plasmid pRS305 in which the ApaI site had been deleted. The linear $A p a$ I fragment was used for the integrative transformation at the $S L Y 1$ locus.

Run-on transcription. Run-on transcription was carried out as described elsewhere $(6,43)$. Briefly, cells are permeabilized with the detergent $N$-lauroyl sarcosine (Sigma catalog number L-5125) and incubated briefly with a transcription mix containing $\left[\alpha-{ }^{32}\right.$ P $]$ UTP. Transcription occurs at a rapid rate but ceases after 3 to $5 \mathrm{~min}$. This appears to represent the addition of nucleotides to previously initiated transcripts, since the size of the labeled product is heterogeneous, ranging from $<200$ to $>5,000$ nucleotides. The RNA was prepared and hybridized to slot blots containing the indicated genes cloned into the single-stranded f1 phage R229.

Transcription and processing of rRNA. A culture was grown at $23^{\circ} \mathrm{C}$ in a medium lacking methionine, moved to a water bath at $37^{\circ} \mathrm{C}$, and incubated for $90 \mathrm{~min}$. The transcription of rRNA was detected by means of the posttranscriptional incorporation of methyl groups (40). The cells were pulse-labeled with $\left[\mathrm{C}^{3} \mathrm{H}_{3}\right]$ methionine $(60 \mu \mathrm{Ci} / \mathrm{ml})$ and chased by the addition of cold methionine $(500 \mu \mathrm{g} / \mathrm{ml})(43)$. The reaction was terminated by addition of sterile crushed ice. Total RNA was prepared from harvested cells by the hot phenol method (5).
RNA samples were applied on a $1.5 \%$ agarose gel in formaldehyde. The agarose gel was soaked with $\mathrm{En}^{3} \mathrm{Hance}$ (NENDupont), washed in cold water, dried, and visualized by fluorography at $-70^{\circ} \mathrm{C}$.

Analysis of posttranslational modification of CPY. Cells were grown at $23^{\circ} \mathrm{C}$ in a medium minus methionine to an optical density at $600 \mathrm{~nm}$ of 0.3 to 0.5 . Cells were divided into two portions; one was incubated at $23^{\circ} \mathrm{C}$ and the other was incubated at $37^{\circ} \mathrm{C}$ for $90 \mathrm{~min}$. Cells $\left(2.5 \times 10^{7}\right)$ were pelleted and resuspended in $1.0 \mathrm{ml}$ of prewarmed fresh medium containing $150 \mu \mathrm{Ci}$ of Expre ${ }^{35} \mathrm{~S}^{35} \mathrm{~S}$ (NEN-Dupont) label. After $60 \mathrm{~min}$ of radiolabeling, the cells were chased for $30 \mathrm{~min}$ by the addition of $10 \mu \mathrm{l}$ of a solution containing $0.1 \%$ cysteine, $0.4 \%$ methionine, and $100 \mathrm{mM}\left(\mathrm{NH}_{4}\right)_{2} \mathrm{SO}_{4}$. Cells were maintained at 23 or $37^{\circ} \mathrm{C}$ during the pulse and chase as specified. Incubation was terminated by addition of cycloheximide to $100 \mu \mathrm{g} / \mathrm{ml}$ and $\mathrm{NaN}_{3}$ to $10 \mathrm{mM}$ and then by a chilling on ice. Cell extracts were prepared as described by Rose et al. (32) and immunoprecipitated with anti-carboxypeptidase Y (CPY) serum $(2.5 \mu \mathrm{l})$ (provided through $\mathrm{P}$. Walter) at $4^{\circ} \mathrm{C}$ overnight followed by addition of protein A-Sepharose 4B. Immunoabsorbed protein was fractionated on a sodium dodecyl sulfate (SDS) $-7.5 \%$ polyacrylamide gel.

\section{RESULTS}

Isolation of a $t s$ mutant deficient in ribosomal protein gene transcription. A collection of $t s$ mutants of $S$. cerevisiae (38) was screened for those defective in the accumulation of mRNA for ribosomal proteins at the restrictive temperature. Most of the mutants had normal levels of ribosomal protein mRNA. A few had the characteristics of a splicing defect (31). However, Northern analysis of RNA prepared from mutant 312 showed that at the restrictive temperature this strain had almost no mRNA for ribosomal proteins L3, L29, L32, YL8, and S10 (Fig. 1). In contrast, the levels of actin and pyruvate kinase mRNA were normal, whereas the mRNA for Eno1p, previously identified as a heat shock protein (13), was increased. Elongation factor $1 \mathrm{mRNA}$ was decreased, although not as severely as ribosomal protein mRNAs. Splicing appears normal in mutant 312. No accumulation of unspliced transcript from the intron-containing genes $A C T 1, C Y H 2, R P L 32, Y L 8$, or RPS10 was observed (not shown). At the permissive temperature, the doubling time of mutant 312 is $25 \%$ greater than that of wild-type cells.

Pulse-label analysis with $\left[{ }^{35} \mathrm{~S}\right]$ methionine showed that after $90 \mathrm{~min}$ at the nonpermissive temperature, there was only a 20 to $30 \%$ decrease in total protein synthesis. Nevertheless, analysis of the proteins synthesized, by a two-dimensional gel method that displays most of the ribosomal proteins (9), showed that synthesis of essentially all ribosomal proteins was barely detectable (not shown). At that time, cell viability is $\mathbf{7 0}$ to $80 \%$. Thus, the effect of temperature on the transcription of ribosomal protein genes is not the result of nonspecific damage of the cells.

In an effort to demonstrate that the effect observed in mutant 312 was directly on transcription, rather than on the processing or half-life of the transcripts, we carried out a version of run-on transcription that we have developed for $S$. cerevisiae $(6,43)$. The results (Fig. 2) show that at the nonpermissive temperature, the transcription of genes for three ribosomal proteins, L3, L29, and L32, is essentially abolished, while the transcription of genes for two nonribosomal proteins, EF1 and PYK, is relatively unaffected.

Mutant 312 is also deficient in rRNA synthesis. In mutant 312 , $\left[{ }^{3} \mathrm{H}\right]$ uracil incorporation into macromolecules was de- 


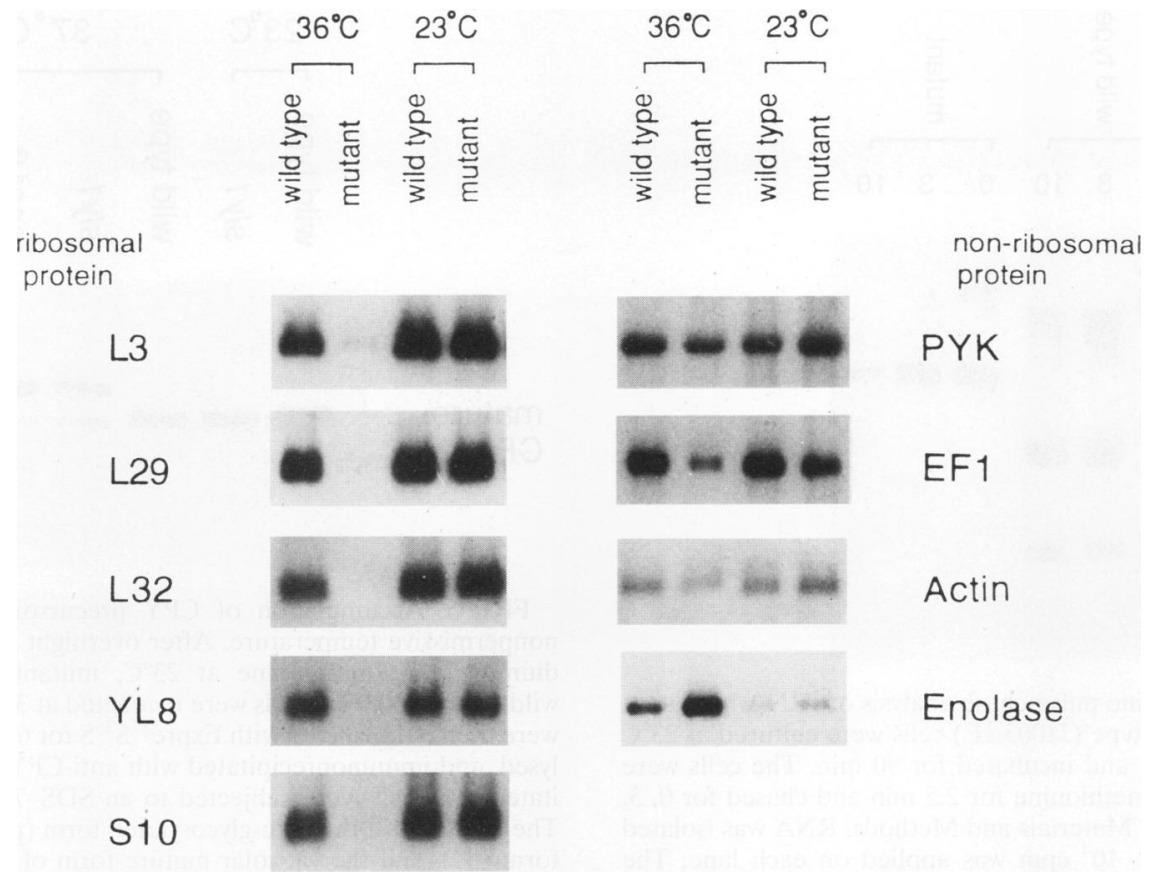

FIG. 1. Northern analysis of $t s$ mutant 312. After overnight culture in YPD medium at $23^{\circ} \mathrm{C}$, mutant 312 and wild-type (J1003.1E) cells were transferred to $36^{\circ} \mathrm{C}$ and incubated for $90 \mathrm{~min}$. Total RNAs $(5 \mu \mathrm{g})$ isolated from the cells were separated by gel electrophoresis, transferred to a nylon filter, and hybridized with radiolabeled RNA probes for RPL3, RPL32, RPS10, ACT1, and PYK1 or DNA probes for RPL29, YL8, ENO1, and TEF1 as described in Materials and Methods.

pressed to less than $10 \%$ after $90 \mathrm{~min}$ at the restrictive temperature (data not shown). As rRNA represents about $60 \%$ of total RNA, this result suggests that rRNA synthesis has essentially stopped. $A\left[\mathrm{C}^{3} \mathrm{H}_{3}\right]$ methionine pulse-chase permits us to follow the synthesis and processing of rRNA, since newly synthesized precursor rRNA is methylated immediately (40). The results are shown in Fig. 3; note that seven times as much RNA from the mutant strain was loaded in the three righthand lanes. It is apparent that the formation of rRNA is reduced by approximately $90 \%$ in the mutant at the restrictive temperature. Furthermore, what little $35 \mathrm{~S}$ precursor RNA that is transcribed is not processed to the intermediate and mature molecules, as expected in a cell synthesizing no ribosomal proteins (44). The presence of almost equal amounts of labeled 35S RNA in the 0- and 3-min chase points indicates that the unprocessed 35S RNA is not rapidly degraded. It eventually declines (10-min chase), with a half-life of 5 to $10 \mathrm{~min}$, consistent with that previously reported (44). Thus, the data represent a real inhibition of transcription and not an ultrarapid turnover of the transcripts.

We conclude that the $t s$ mutation in strain 312 has a drastic effect on the transcription of ribosomal genes, both rRNA genes and ribosomal protein genes. Perhaps this mutation affects a fundamental aspect of ribosome synthesis.

Cloning of the gene that complements the temperature sensitivity of mutant $\mathbf{3 1 2}$. When mutant strain 312 was crossed to the wild-type strain J1003.1E, the heterozygous diploid was not $t s$, showing that the mutation is recessive. On sporulation and dissection of asci, temperature sensitivity for growth segregated $2: 2$, indicating that this phenotype is due to a single mutation in a nuclear gene. The phenotype for the absence of ribosomal protein mRNA at $36^{\circ} \mathrm{C}$ segregated together with temperature sensitivity.

A gene that complements the temperature sensitivity of the

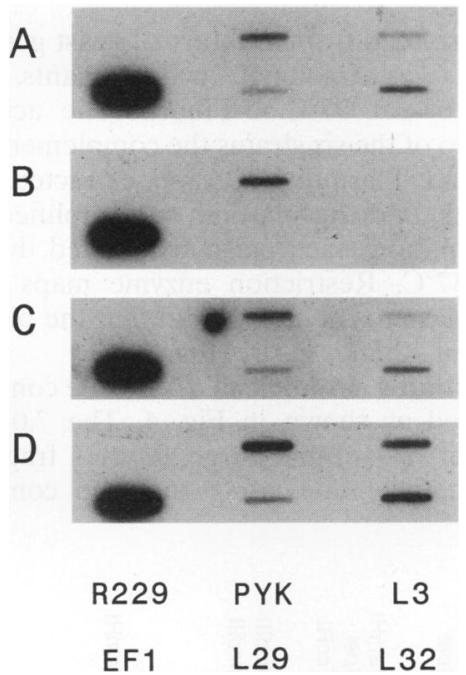

FIG. 2. Run-on transcription analysis of the mutant phenotype. Mutant 312 and wild-type (J1003.1D) cells were cultured at $23^{\circ} \mathrm{C}$ overnight, and an aliquot of each was shifted to $37^{\circ} \mathrm{C}$ for $90 \mathrm{~min}$. Portions of each of the four cultures were harvested on ice, washed, permeabilized, and provided with a transcription mix containing $\left[\alpha-{ }^{32} \mathrm{P}\right]$ UTP (see Materials and Methods) $(6,43)$. After $10 \mathrm{~min}$ at $25^{\circ} \mathrm{C}$, the cells were harvested. RNA was prepared from each sample and subsequently hybridized to nitrocellulose filters on which had been immobilized single-stranded phage genomes carrying the genes for the proteins indicated in the template below. R229 is the phage vector. For each filter, hybridization was carried out with the transcription products of equal numbers of cells. Note that for the mutant at the nonpermissive temperature the total incorporation in the run-on transcription reaction was substantially reduced because the bulk of the transcription is rRNA, which itself is greatly reduced (see Fig. 3). (A and B) Samples from mutant 312 at 23 and $37^{\circ} \mathrm{C}$, respectively; (C and D) samples from $\mathrm{J} 1003.1 \mathrm{D}$ at 23 and $37^{\circ} \mathrm{C}$, respectively. 


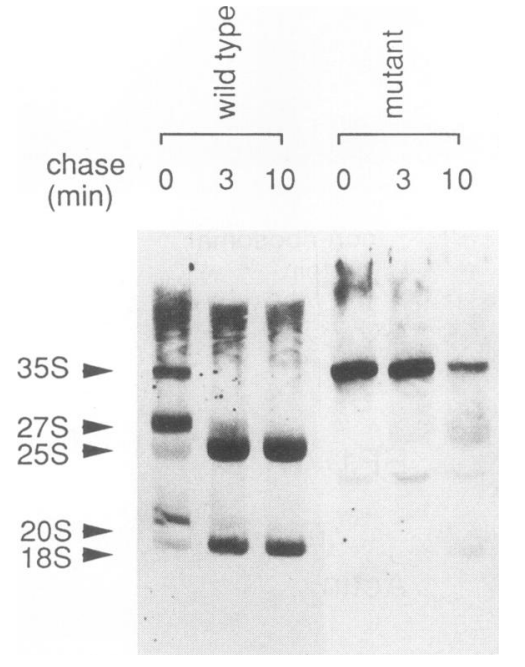

FIG. 3. $\left[\mathrm{C}^{3} \mathrm{H}_{3}\right]$ methionine pulse-chase analysis of rRNA in mutant 312. Mutant 312 and wild-type (J1003.1E) cells were cultured at $23^{\circ} \mathrm{C}$ overnight, moved to $37^{\circ} \mathrm{C}$, and incubated for $90 \mathrm{~min}$. The cells were pulse-labeled with $\left[\mathrm{C}^{3} \mathrm{H}_{3}\right.$ ]methionine for $2.5 \mathrm{~min}$ and chased for 0,3 , and $10 \mathrm{~min}$ as described in Materials and Methods. RNA was isolated from these cells, and $5 \times 10^{4} \mathrm{cpm}$ was applied on each lane. The amounts loaded per lane were, from left to right, 9.1, 10,11,63, 70, and $86 \mu \mathrm{g}$. A fluorograph of the gel is shown. We believe that the band at about $23 \mathrm{~S}$ in the three mutant lanes (right) is an artifact being carried at the front of the overloaded $25 \mathrm{~S}$ rRNA.

mutant 312 was isolated from a library of yeast genomic DNA cloned in YCp50 (33). Among $10^{4}$ transformants, six colonies were able to grow at $37^{\circ} \mathrm{C}$. 5-Fluoroorotic acid selection showed that in two of the six strains the complementing activity was plasmid linked. Plasmid DNA was extracted from these two transformants, and the plasmid was amplified in E. coli. Upon retransformation, each plasmid restored the growth of mutant 312 at $37^{\circ} \mathrm{C}$. Restriction enzyme maps of the two complementing plasmids demonstrated that the plasmids contained an identical 12.5-kb insert (Fig. 4).

Mutant 312 contains a ts allele of SLYI. The complementing gene was localized as shown in Fig. 4. The 7.0-kb HindIII fragment, but not any of the three BamHI fragments, had complementing activity, indicating that the complementing

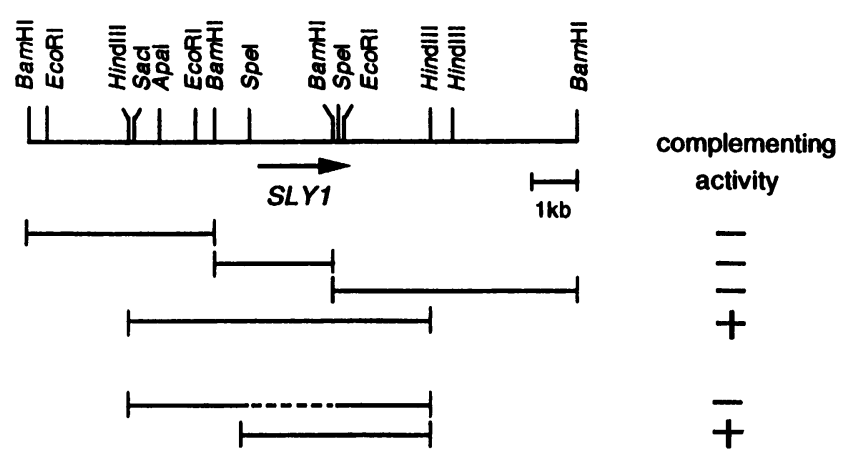

FIG. 4. Mapping of the complementing gene in a clone which complements the temperature sensitivity of mutant 312 . Mutant 312 cells were transformed with plasmids (YCp50) containing various fragments of the isolated clone. The growth of transformants at $37^{\circ} \mathrm{C}$ is expressed as + or - .

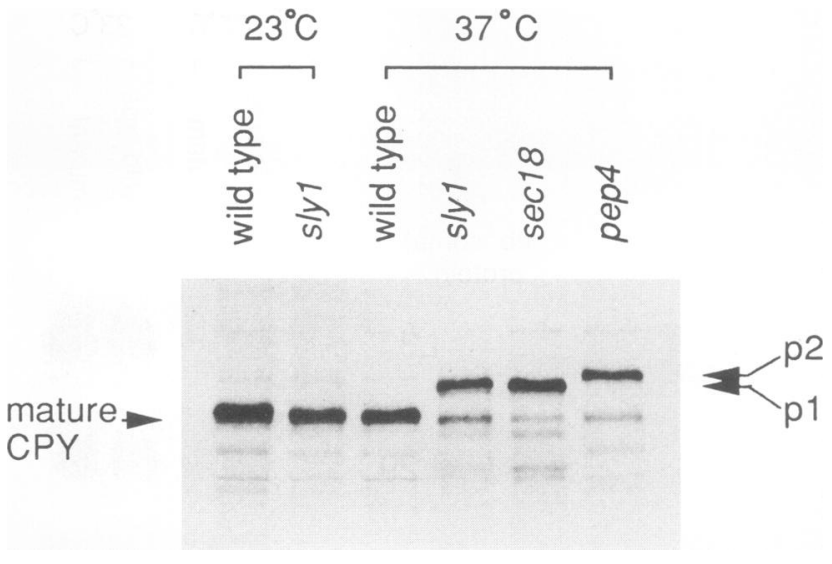

FIG. 5. Accumulation of CPY precursor in mutant 312 at the nonpermissive temperature. After overnight culture in minimum medium without methionine at $23^{\circ} \mathrm{C}$, mutant 312 , sec 18 , pep4, and wild-type (J1003.1E) cells were incubated at $37^{\circ} \mathrm{C}$ for $90 \mathrm{~min}$. The cells were then radiolabeled with Expre ${ }^{35} \mathrm{~S}^{35} \mathrm{~S}$ for $60 \mathrm{~min}$, chased for $30 \mathrm{~min}$, lysed, and immunoprecipitated with anti-CPY antiserum. The precipitated materials were subjected to an SDS-7.5\% polyacrylamide gel. The positions of the core-glycosylated form ( $\mathrm{p} 1)$, the fully glycosylated form (p2), and the vacuolar mature form of CPY are indicated. The lower band in the mutant cells at $37^{\circ} \mathrm{C}$ may be unprocessed prepro$\mathrm{CPY}$, which is poorly resolved from mature CPY.

gene contains one or both of the two BamHI sites in this plasmid. Sequence analysis from the appropriate BamHI site revealed 300 nucleotides with perfect identity to the $S L Y 1$ gene (4). The restriction map also agreed with that of $S L Y 1$. Another open reading frame, not previously identified, includes the other $B a m H I$ site. To establish that $S L Y 1$ is the complementing gene, two deletions were analyzed. The HindIII fragment with a deletion between the two SpeI sites (Fig. 4) was unable to complement, while a $4.2-\mathrm{kb}$ portion of the HindIII fragment that contains the entire $S L Y 1$ gene retained complementing activity. These results suggest that $S L Y 1$ complements the temperature sensitivity of the mutant 312 .

Mutant 312 could have a ts allele of $S L Y 1$, or $S L Y 1$ could be a suppressor. To distinguish between these alternatives, $S L Y 1$ was integrated into the mutant strain as described in Materials and Methods. Crossing with a wild-type haploid and dissection of eight tetrads yielded 32 spores that grew at $37^{\circ} \mathrm{C}$. This result indicates that mutant 312 carries a $t s$ allele in $S L Y 1$.

Map position of $S L Y 1$. The $S L Y 1$ clone was matched to a set of bacteriophage $\lambda$ clones that forms a contig map of the $S$. cerevisiae genome (30). SLY1 hybridizes to the overlapping clones 4040 and 6708 , placing it on the right arm of chromosome IV between $A R O 1$ and $R A D 9$. It is interesting that $S E C 1$, $S E C 5$, and SEC7 also map to that region (24).

The mutant 312 is defective in protein secretion at the restrictive temperature. An allele of $S L Y 1$ was originally isolated as a single-copy suppressor of defects in Ypt1p, a protein which is essential for protein transport from the ER to the Golgi apparatus (4). The essential SLY1 gene product also acts at a similar step in secretion (28). To establish whether the $s l y 1 t s$ mutant is defective in protein secretion at the restrictive temperature, the processing of the vacuolar enzyme CPY was examined (Fig. 5). In contrast to wild-type cells, the mutant cells accumulated a significant amount of core-glycosylated ER (form p1) at the nonpermissive temperature, just as occurs in a sec18-1 mutant. Fully glycosylated CPY precursor (form p2), 


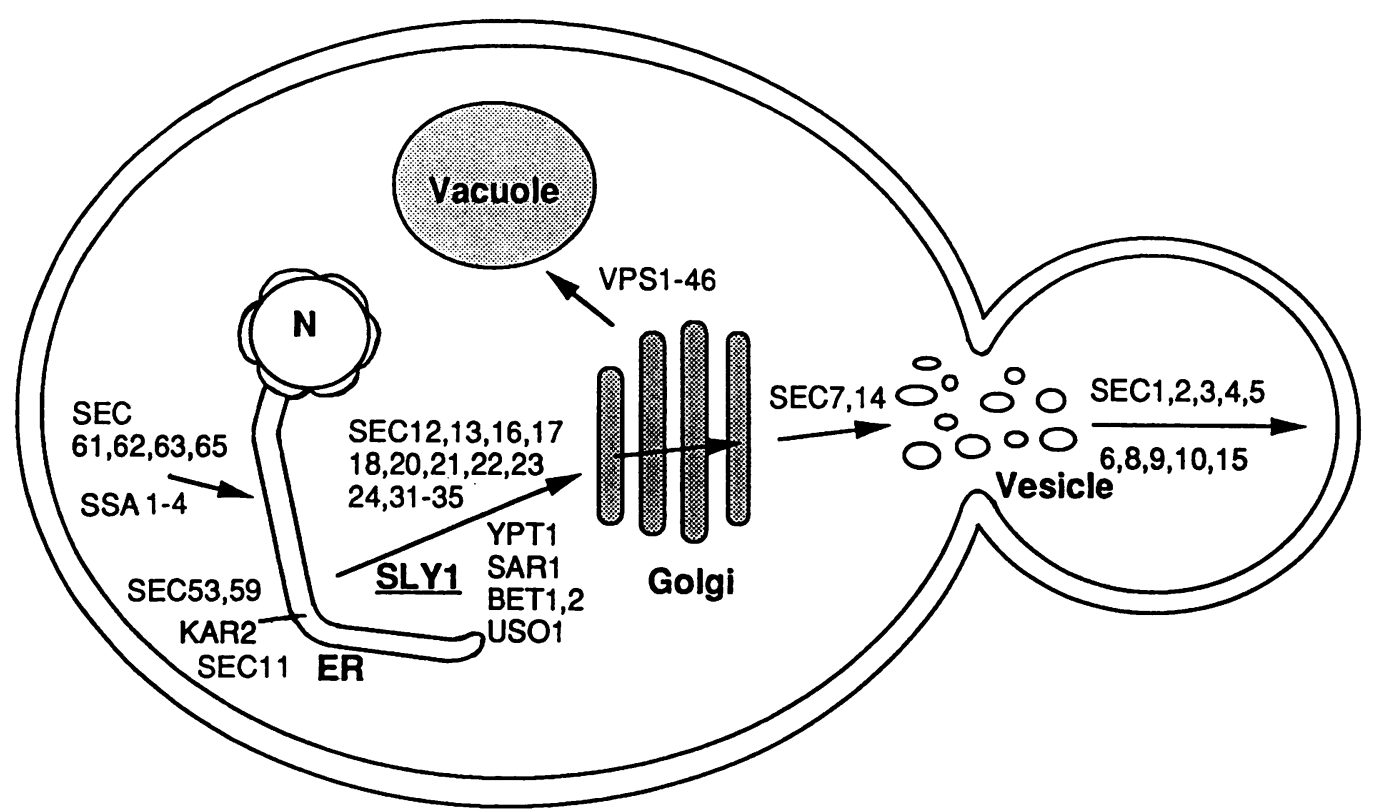

FIG. 6. The secretory pathway in $S$. cerevisiae. This model is adapted from reference 26 .

which accumulates in the protease-deficient pep 4 strain, was not observed in slyl ts cells. This result indicates that, at the nonpermissive temperature, this sly 1 mutant is defective in transport between the ER and the Golgi apparatus.

A defect in both elements of ribosome synthesis is a general feature of sec mutants. Why is a sly1 ts mutant defective in the synthesis of ribosome components? One possibility is that Sly1p has some special role in ribosome synthesis. Another is that the secretion pathway is required for ribosome synthesis. To ask whether the effect of the $t s$ allele on ribosome synthesis is specific for the slyl mutation or is a general result of the inactivation of the secretory pathway, we assayed rRNA transcription and the levels of ribosomal protein mRNA in cells carrying $t s$ alleles of $\sec 1, \sec 7, \sec 14$, and $\sec 18$, representing diverse steps in the secretory pathway (27) (Fig. 6). Figure 7 shows the rRNA transcription in these sec mutants. At $23^{\circ} \mathrm{C}$, transcription and processing of rRNA in each mutant is similar to that in wild-type cells. At the restrictive temperature, both the transcription and the processing of the $35 \mathrm{~S}$ rRNA precursor are reduced in each of the sec mutants, although not to as great an extent as with the sly1 mutant. Although some of the difference may be due to leaky alleles, especially sec14 and to a lesser extent $\sec 7$ (39), the data suggest that sly1 has an effect beyond its role in the secretion pathway.

Figure 8A shows mRNA levels in these $t s$ sec mutants. After $90 \mathrm{~min}$ at $36^{\circ} \mathrm{C}$, each mutant has a very low level of mRNA of encoding ribosomal proteins L3, L29, L32, YL8, S10, A0, and L44. In this analysis, the mutant carrying the sly1 ts allele also has the lowest level of mRNA of ribosomal proteins. The level of mRNA of $A C T 1$ and $P Y K 1$ is maintained normally at $36^{\circ} \mathrm{C}$, while that of $E N O 1$ is increased, as expected. Figure $8 \mathrm{~B}$ shows that sec63 (35) and sec53 (1) mutants, in which the secretory pathway is blocked either before or within the ER, respectively, also affect the transcription of ribosomal protein genes. A sec 11 mutant gave a similar result (not shown). These results indicate that mutations throughout the secretory pathway have a profound effect on the transcription of ribosomal protein genes.

BFA leads to a decrease of ribosomal protein mRNA. The shift from 23 to $36^{\circ} \mathrm{C}$ necessary to assay the effects of a $t s$ allele brings about a transient inhibition of the transcription of ribosomal protein genes $(9,16)$. While it is apparent that the wild-type cells have returned to a normal level of transcription by the time the samples were taken in Fig. 1 and 8 , we wished

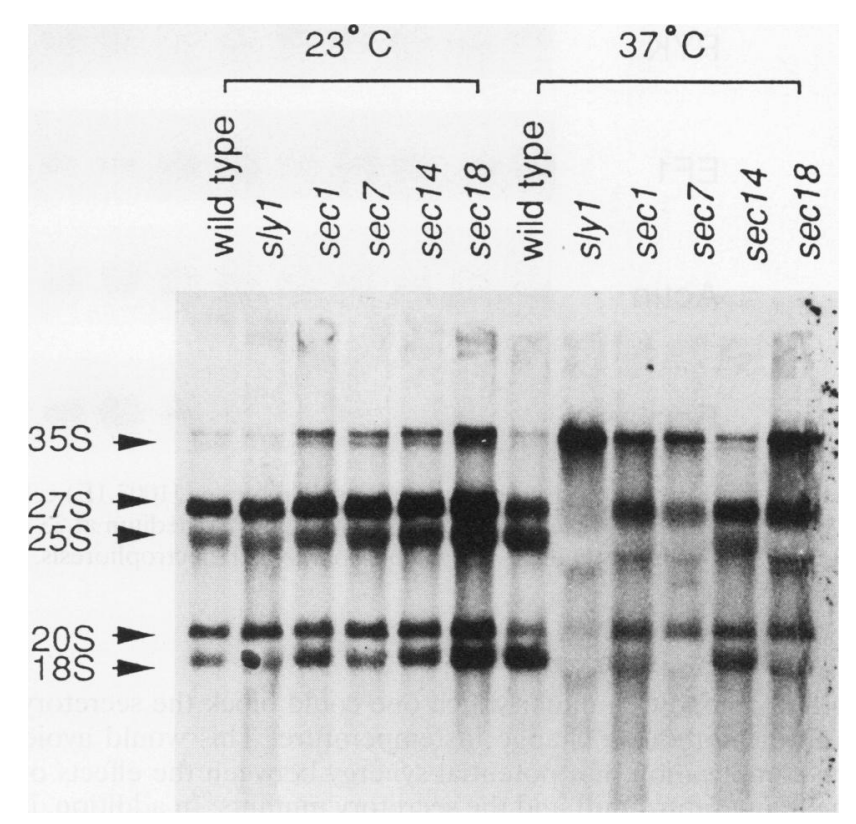

FIG. 7. $\left[\mathrm{C}^{3} \mathrm{H}_{3}\right]$ methionine pulse-labeling of rRNA in sec mutants. Wild-type (J1003.1E) cells and sly1, sec1, sec7, sec14, and sec18 mutants grown in dropout medium without methionine at $23^{\circ} \mathrm{C}$ overnight were shifted to $37^{\circ} \mathrm{C}$, incubated for $90 \mathrm{~min}$, and labeled with $\left[\mathrm{C}^{3} \mathrm{H}_{3}\right]$ methionine for $5 \mathrm{~min}$. Total RNA was isolated from each culture. RNA containing $4 \times 10^{4} \mathrm{cpm}$ from each culture was analyzed on a gel. Samples from the mutants at $37^{\circ} \mathrm{C}$ contained 3 to 10 times more RNA than those at $23^{\circ} \mathrm{C}$. A fluorograph of the gel is shown. 
A

ribosomal
protein

L3

L29

L32

YL8

S10

AO

$\llcorner 44$

non-ribosomal protein

PYK

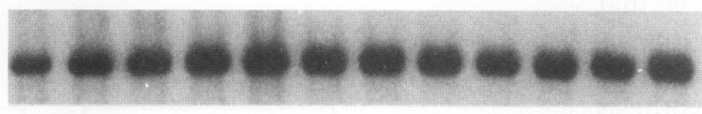

EF1

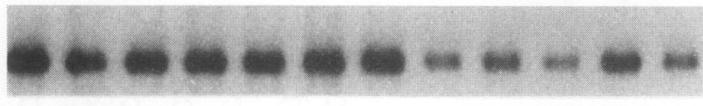

Actin
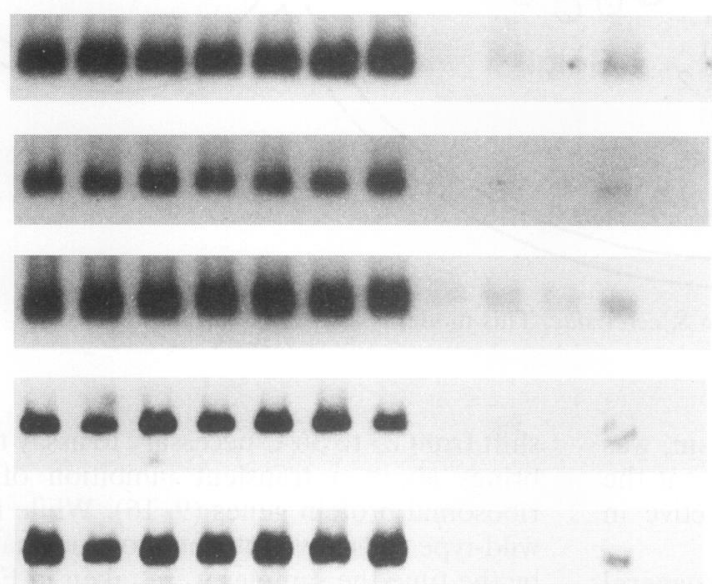

Enolase
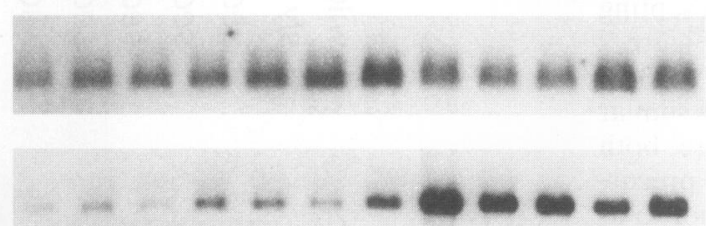

ribosomal protein

L3

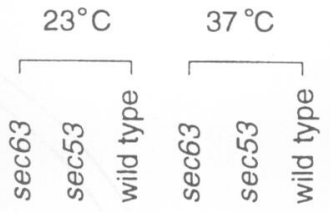

L32

non-ribosomal protein

PYK

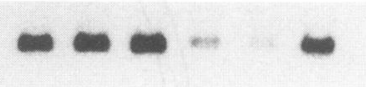

L29

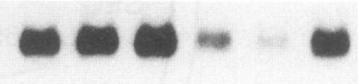

Actin
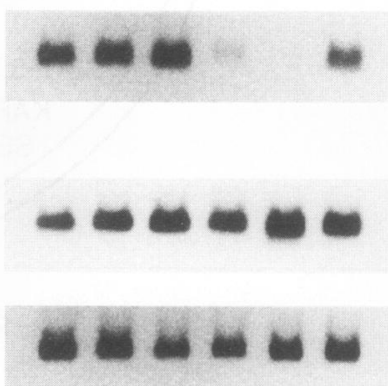

FIG. 8. Northern analysis of $\sec$ mutants. Wild-type (J1003.1E) cells and $\operatorname{sly} 1$ (mutant 312 ), $\sec 1$, sec7, $\sec 14$, and $\sec 18$ strains (A) or wild-type (J1003.1E), sec63, and sec53 strains (B) grown in YPD medium at $23^{\circ} \mathrm{C}$ overnight were transferred to $36^{\circ} \mathrm{C}$ and incubated for 90 min. Total RNAs $(5 \mu \mathrm{g})$ isolated from the cells were separated by gel electrophoresis, transferred to a nylon filter, and hybridized with radiolabeled RNA probes or DNA probes.

to find a condition under which one could block the secretory pathway without a change in temperature. This would avoid the complication of a potential synergy between the effects of the temperature shift and the secretory mutants. In addition, it would permit us to examine the time course of the effect of a deficient secretory pathway on ribosome synthesis. In mammalian cells, brefeldin A (BFA) inhibits protein transport from the ER to the Golgi apparatus and causes a redistribution of Golgi apparatus resident proteins into the ER $(18,21)$. Recently, Vogel et al. (41) showed that treatment with BFA of a $S$. cerevisiae strain carrying a deletion of the ERG6 gene causes a block in secretion similar to that in mammalian cells (8). This permits one to examine the effect on ribosome synthesis of a block in the secretory pathway, without the complications of a heat shock. After addition of BFA, the level of mRNA of ribosomal protein genes in erg6 $\Delta$ cells, but not in wild-type cells, declined rapidly, with a half-life of less than 30 min (Fig. 9). Similar results were obtained after the cells were treated with tunicamycin $(25,32)$, although the decline in mRNA for ribosomal proteins was somewhat slower (data not shown). These results demonstrate that the effect of the mutants is not related to temperature shock and confirm our conclusion that continued function of the secretory pathway is essential for ribosome synthesis. 


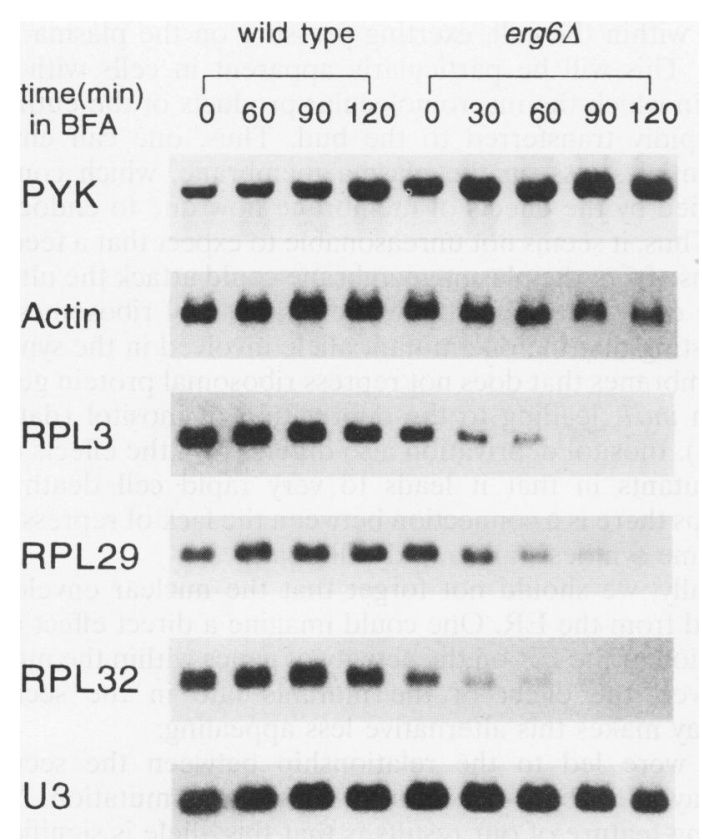

FIG. 9. Effects of BFA on the level of ribosomal protein mRNA. After overnight culture in minimal medium at $30^{\circ} \mathrm{C}$, BFA (final concentration, $50 \mu \mathrm{g} / \mathrm{ml}$ ) was added to wild-type (R757) or erg6 deletion mutant (MD59) cells. After the indicated time intervals, cells were collected. Total RNAs $(5 \mu \mathrm{g})$ isolated from the cells were separated by gel electrophoresis, transferred to a nylon filter, and hybridized with radiolabeled oligonucleotide probes specific for $R P L 3$, RPL29, RPL32 ACT1, PYK1, and U3 RNA. The last is a convenient control (see Materials and Methods).

Is a protein that passes through the secretion pathway essential for ribosome synthesis? A simple explanation of the results presented above is that a protein(s) that utilizes the secretory pathway is essential for ribosome synthesis. If that were the case, then partially blocking protein synthesis as well as blocking secretion would have an additive effect on the transcription of ribosomal protein genes. To test this possibility, cells were treated, shortly before the temperature shift, with a low level of cycloheximide, sufficient to reduce protein synthesis to about $10 \%$ of normal. The results (Fig. 10) show that, rather than augmenting the effect of a defective secretory pathway, the slowing of protein synthesis abolishes it. Although such an experiment must be viewed with caution because of the possibility of unexpected effects of cycloheximide, e.g., greatly extending the half-life of the mRNA, it suggests that the effect of the secretion pathway is due not to the deficiency of an essential protein but to a more global aspect of the interaction between membrane synthesis and ribosome synthesis.

A cis-acting element upstream of a ribosomal protein gene responds to the secretion defect. In order to ask whether it is the promoter region of ribosomal protein genes that is responsive to the disruption of the secretory pathway, we constructed plasmids carrying the $R P L 32$ promoter driving lac $Z$ or the $A D H 1$ promoter driving RPL32 cDNA. Northern analysis (Fig. 11) shows that at the nonpermissive temperature the RPL 32 mRNA derived from the $A D H 1$ promoter is slightly less in sly1 (lane 2) than in wild-type (lane 4) cells, perhaps because the cells are growing more slowly. On the other hand, the RPL32lac $Z$ transcript essentially disappears in sly1 (lane 6) compared

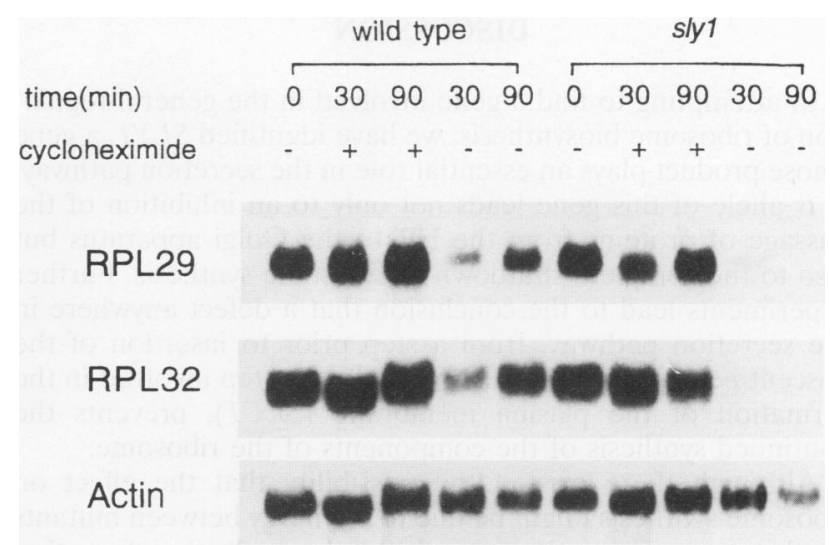

FIG. 10. Partial inhibition of protein synthesis blocks the effect of the secretory pathway on ribosome synthesis. After overnight culture in YPD medium at $23^{\circ} \mathrm{C}$, wild-type (J1003.1E) and slyl cells were shifted to $36^{\circ} \mathrm{C}$ with or without cycloheximide $(1.5 \mu \mathrm{g} / \mathrm{ml})$ and incubated for the indicated time intervals. Total RNAs $(5 \mu \mathrm{g})$ isolated from the cells were separated by gel electrophoresis, transferred to a nylon filter, and hybridized with radiolabeled RNA probes for RPL29, RPL32, and ACT1.

with in wild-type cells (lane 8). (Note that the mRNA derived from the genomic RPL32 is not visible at this exposure. A longer exposure shows that it behaves as shown in Fig. 1.) This result demonstrates that the upstream region of RPL32 has a cis-acting element sensitive to a defect in the secretory pathway and supports our conclusion that such a defect leads to a reduction in the transcription of ribosomal protein genes.

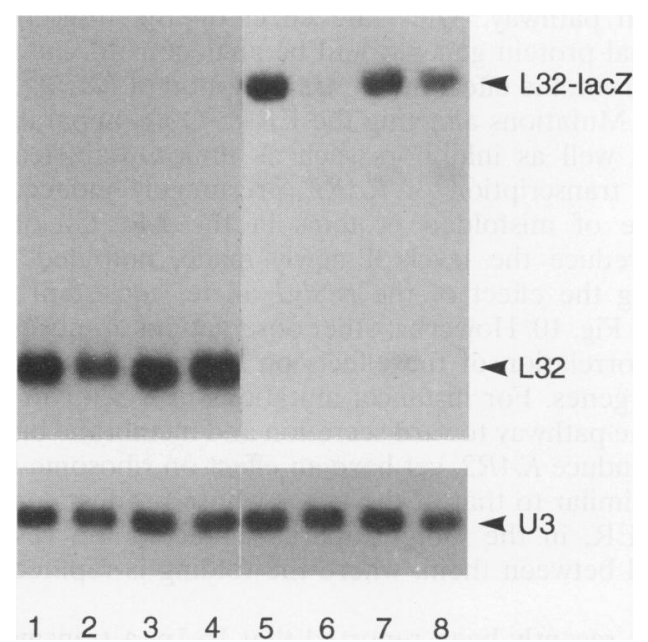

FIG. 11. Effects of promoter on transcription after temperature shift-up. Mutant 312 (lanes 1, 2, 5, and 6) and J1003.1E (lanes 3, 4, 7, and 8) cells were transformed with vector YEp351 containing the $A D H 1$ promoter driving RPL32 cDNA (lanes 1 to 4 ) or the vector YEp357 containing the RPL32 promoter driving the first exon of $R P L 32$ fused to lacZ (lanes 5 to 8 ) and cultured in selective medium at $23^{\circ} \mathrm{C}$. The cells were shifted to $36^{\circ} \mathrm{C}$ and incubated for $90 \mathrm{~min}$. Total RNA $\left(5 \mu \mathrm{g}\right.$ ) isolated from each culture at $23^{\circ} \mathrm{C}$ (lanes $1,3,5$, and 7 ) and at $36^{\circ} \mathrm{C}$ (lanes $2,4,6$, and 8 ) was separated by gel electrophoresis, transferred to a nylon filter, and hybridized with radiolabeled oligonucleotide probes for exon 1 of RPL32 and for U3 small nuclear RNA. 


\section{DISCUSSION}

In attempting to find a gene involved in the general regulation of ribosome biosynthesis, we have identified $S L Y 1$, a gene whose product plays an essential role in the secretion pathway. A $t s$ allele of this gene leads not only to an inhibition of the passage of proteins from the ER to the Golgi apparatus but also to the complete shutdown of ribosome synthesis. Further experiments lead to the conclusion that a defect anywhere in the secretion pathway, from a step prior to insertion of the nascent peptide into the ER (SEC63) to a step involved in the formation of the plasma membrane (SEC1), prevents the continued synthesis of the components of the ribosome.

Although there existed the possibility that the effect on ribosome synthesis might be due to a synergy between mutants in the secretory pathway and the heat shock effect that transiently inhibits ribosome synthesis, we were able to reproduce the effect without a temperature shift, by using the inhibitors of the secretory pathway, BFA and tunicamycin. In the presence of BFA, the mRNA for ribosomal proteins disappeared with a half-life of less than $30 \mathrm{~min}$. Since the normal half-life of mRNA for ribosomal proteins at $23^{\circ} \mathrm{C}$ is 10 to $15 \mathrm{~min}$ (17), disruption of the secretory pathway must impact ribosome synthesis within $15 \mathrm{~min}$, suggesting a rather intimate relationship between the two.

Several possible mechanisms for this relationship suggest themselves. One is that a protein transported through the secretion pathway is essential for ribosome synthesis. Without defining how such a protein could be necessary, the experiment illustrated in Fig. 10 argues persuasively against its existence. The presence of cycloheximide, rather than enhancing the effect of the $t s$ allele of $s l y 1$, counteracts it. Possible explanations for this result are discussed below. These data also demonstrate that the effects of BFA and of the sec mutants are not simply due to nonspecific disturbance of the cell.

A second possibility is that the inhibition of ribosome synthesis could be a stress-related response to a defect in the secretion pathway. Thus, the effect on the transcription of ribosomal protein genes would be analogous to, but opposite in sign from, the effect on the transcription of $K A R 2(3,19,23$, $25,32)$. Mutations affecting the ER-to-Golgi apparatus transport, as well as inhibitors such as tunicamycin, lead to increased transcription of $K A R 2$, presumably induced by the presence of misfolded proteins in the ER. Cycloheximide would reduce the level of newly made, unfolded proteins, lessening the effect of the ts sly1 allele, consistent with the result in Fig. 10. However, other observations argue against the direct correlation of the effects on $K A R 2$ and the ribosomal protein genes. For instance, mutations in sec7 or in sec1, far along the pathway toward secretion and membrane biogenesis, do not induce $K A R 2$, yet have an effect on ribosome synthesis that is similar to that of the genes whose products participate in the ER, in the Golgi apparatus, and in the vesicles exchanged between them, where the folding is reputed to take place.

It has recently been reported that Ire $1 \mathrm{p}$, a transmembrane protein kinase required for inositol prototrophy, is required for the induction of $K A R 2$ transcription in response to defects in the secretory pathway $(3,22)$. A test of its effects on the inhibition of transcription of ribosomal protein genes is under way.

A third possibility is that there is an interaction between the synthesis of the plasma membrane and the synthesis of ribosomes. A defect anywhere in the secretory pathway will lead rapidly to a failure to add to the plasma membrane. Continuing protein synthesis will increase the concentration of macromol- ecules within the cell, exerting pressure on the plasma membrane. This will be particularly apparent in cells with small buds, in which the macromolecular products of the entire cell are rapidly transferred to the bud. Thus, one can envision substantial stress on the plasma membrane, which could be amplified by the effects of membrane flow due to endocytosis (29). Thus, it seems not unreasonable to expect that a feedback response from the plasma membrane could attack the ultimate source of its distress, namely, the synthesis of ribosomes. It is interesting that the one mutant allele involved in the synthesis of membranes that does not repress ribosomal protein genes is that in inol, leading to the deprivation of inositol (data not shown). Inositol deprivation also differs from the effects of the sec mutants in that it leads to very rapid cell death (11). Perhaps there is a connection between the lack of repression of ribosome synthesis and rapid cell death.

Finally, we should not forget that the nuclear envelope is formed from the ER. One could imagine a direct effect of the depletion of the ER on the activity of genes within the nucleus. However, the effect of the mutants late in the secretory pathway makes this alternative less appealing.

We were led to the relationship between the secretion pathway and ribosome synthesis by the slyl mutation. Yet, a puzzling feature of our results is that this allele is significantly more effective at inhibiting ribosome synthesis, especially rRNA transcription, than are the $t s$ alleles of the other mutants in the secretory pathway. Sly $1 p$ is an essential protein (28) that is highly charged and lacks a signal sequence (4) but nevertheless is tightly membrane associated (36a). The distinctive effects of the ts sly1 allele (Fig. 7) suggest that it has functions other than participating in vesicle trafficking between the ER and the Golgi apparatus.

It is interesting that the transcription of the genes for the acidic ribosomal proteins A0 and L44 are regulated in parallel with the other ribosomal proteins (Fig. 8A). A0 and L44 are not assembled onto the ribosome in the nucleolus but are exchanged on and off the ribosome repeatedly in the cytoplasm $(36,46)$. They are in molar excess over other ribosomal proteins.

It is remarkable that the synthesis of roughly 80 ribosomal proteins, encoded by more than 125 genes, can be coordinated with the precision shown in Fig. 1, 8, and 9. This regulation, responding to the failure of the secretory pathway, appears to be mediated by sequences upstream of the transcription unit. Most ribosomal protein genes have two sites for the DNAbinding protein Rap1p, which has been implicated in the transcription of these genes and in its regulation $(34,37,45)$. A few of the ribosomal protein genes, e.g., $T C M 1$, have no sites for Rap1p but have one for Abf1p instead (10). However, in the several experimental situations examined to date, the transcription of all the ribosomal protein genes appears to be coordinate $(12,15)$. On the other hand, many genes that have Rap1p sites are not regulated in parallel with the ribosomal proteins. This is clearly apparent from Fig. 8A. While $P Y K 1$, $E N O 1$, and $T E F 1$ each have one or more Rap1p sites upstream of the transcription unit (reviewed in reference 2), the secretory mutants have a mild effect on transcription of $T E F 1$, have little if any effect on $P Y K 1$, and actually stimulate ENO1.

Are we approaching the ultimate signal for the regulation of ribosome synthesis? A few points recommend caution. Preliminary experiments suggest that the transcription of 5S RNA, as measured by the 5S/tRNA ratio, is not affected by the ts sly1 allele. While rRNA transcription is severely depressed by a mutation in sly1, it is far less depressed by mutations in other $S E C$ genes (Fig. 7). Nevertheless, the failure of the secretion pathway profoundly affects the transcription of roughly 125 
ribosomal protein genes, inhibits the transcription of rRNA, and halts the synthesis of ribosomes. It seems likely that this represents a signal that is fundamental to the balanced synthesis of the components of the cell.

\section{ACKNOWLEDGMENTS}

We are grateful to L. Alksne, D. Baronas-Lowell, Q. Ju, and L. Neigeborn for preparing the $t s$ bank; to K. Shuai for the initial screen; to $M$. D. Rose for providing the yeast genomic library; to P. Novick, $R$. Schekman, R. F. Gaber, S. Ferro-Novick, and B. Jones for providing yeast strains; to J. P. G. Ballesta for plasmids; and to P. Walter, P. Novick, D. Shields, L. Marsh, M. Kielian, and J. Marmur for helpful discussions. We thank M. Studeny for technical assistance and A. Greaney for secretarial assistance.

This research was supported by National Institutes of Health grants GM25532 (to J.R.W.) and CA13330, which supports the Cancer Center of the Albert Einstein College of Medicine. K.M. was supported by a fellowship from the Ministry of Education of Japan.

\section{REFERENCES}

1. Bernstein, M., W. Hoffmann, G. Ammerer, and R. Schekman. 1985. Characterization of a gene product (Sec53p) required for protein assembly in the yeast endoplasmic reticulum. J. Cell Biol. 101:2374-2382.

2. Buchman, A. R., N. F. Lue, and R. D. Kornberg. 1988. Connections between transcriptional activators, silencers, and telomeres as revealed by functional analysis of a yeast DNA-binding protein. Mol. Cell. Biol. 8:5086-5099.

3. Cox, J. S., C. E. Shamu, and P. Walter. 1993. Transcriptional induction of genes encoding endoplasmic reticulum resident proteins requires a transmembrane protein kinase. Cell 73:1197-1206.

4. Dascher, C., R. Ossig, D. Gallwitz, and H. D. Schmitt. 1991. Identification and structure of four yeast genes $(S L Y)$ that are able to suppress the functional loss of YPT1, a member of the $R A S$ superfamily. Mol. Cell. Biol. 11:872-885.

5. Elion, E. A., and J. R. Warner. 1984. The major promoter element of rRNA transcription in yeast lies $2 \mathrm{~kb}$ upstream. Cell 39:663-673.

6. Elion, E. A., and J. R. Warner. 1986. An RNA polymerase I enhancer in Saccharomyces cerevisiae. Mol. Cell. Biol. 6:20892097.

7. Eng, F. J., and J. R. Warner. 1991. Structural basis for the regulation of splicing of a yeast messenger RNA. Cell 65:797-804.

8. Gaber, R. F., D. M. Copple, B. K. Kennedy, M. Vidal, and M. Bard. 1989. The yeast gene ERG6 is required for normal membrane function but is not essential for biosynthesis of the cell-cyclesparking sterol. Mol. Cell. Biol. 9:3447-3456.

9. Gorenstein, C., and J. R. Warner. 1976. Coordinate regulation of the synthesis of eukaryotic ribosomal proteins. Proc. Natl. Acad. Sci. USA 73:1547-1551.

10. Hamil, K. G., H. G. Nam, and H. M. Fried. 1988. Constitutive transcription of yeast ribosomal protein gene TCM1 is promoted by uncommon cis- and trans-acting elements. Mol. Cell. Biol. 8:4328-4341.

11. Henry, S. A., K. D. Atkinson, A. I. Kolat, and M. R. Culbertson. 1977. Growth and metabolism of inositol-starved Saccharomyces cerevisiae. J. Bacteriol. 130:472-479.

12. Herruer, M. H., W. H. Mager, L. P. Woudt, R. T. Nieuwint, G. M. Wassenaar, P. Groeneveld, and R. J. Planta. 1987. Transcriptional control of yeast ribosomal protein synthesis during carbon-source upshift. Nucleic Acids Res. 15:10133-10144.

13. Iida, H., and I. Yahara. 1985. Yeast heat-shock protein of $M_{\mathrm{r}}$ 48,000 is an isoprotein of enolase. Nature (London) 315:688-690.

14. Ju, Q., and J. R. Warner. Ribosome synthesis during the growth cycle of Saccharomyces cerevisiae. Yeast, in press.

15. Kief, D. R., and J. R. Warner. 1981. Coordinate control of syntheses of ribosomal ribonucleic acid and ribosomal proteins during nutritional shift-up in Saccharomyces cerevisiae. Mol. Cell. Biol. 1:1007-1015.

16. Kim, C. H., and J. R. Warner. 1983. Mild temperature shock alters the transcription of a discrete class of Saccharomyces cerevisiae genes. Mol. Cell. Biol. 3:457-465.

17. Kim, C. H., and J. R. Warner. 1983. Messenger RNA for riboso- mal proteins in yeast. J. Mol. Biol. 165:79-89.

18. Klausner, R. D., J. G. Donaldson, and J. Lippincott-Schwartz. 1992. Brefeldin A: insights into the control of membrane traffic and organelle structure. J. Cell. Biol. 116:1071-1080.

19. Kohno, K., K. Normington, J. Sambrook, M.-J. Gething, and K. Mori. 1993. The promoter region of the yeast KAR2 (BiP) gene contains a regulatory domain that responds to the presence of unfolded proteins in the endoplasmic reticulum. Mol. Cell. Biol. 13:877-890.

20. Maaloe, O., and N. O. Kjeldgaard. 1966. Control of macromolecular synthesis. W. A. Benjamin, Inc., New York.

21. Misumi, Y., K. Miki, A. Takatsuki, G. Tamura, and Y. Ikehara. 1986. Novel blockade by brefeldin A of intracellular transport of secretory proteins in cultured rat hepatocytes. J. Biol. Chem. 261:11398-11403

22. Mori, K., W. Ma, M. J. Gething, and J. Sambrook. 1993. A transmembrane protein with a cdc2 +/CDC28-related kinase activity is required for signaling from the ER to the nucleus. Cell 74:743-756.

23. Mori, K., A. Sant, K. Kohno, K. Normington, M.-J. Gething, and J. F. Sambrook. 1992. A 22 bp cis-acting element is necessary and sufficient for the induction of the yeast KAR2 (BiP) gene by unfolded proteins. EMBO J. 11:2583-2593.

24. Mortimer, R. K., C. R. Contopoulou, and J. S. King. 1991. Genetic and physical maps of Saccharomyces cerevisiae, p. 737-752. In J. R. Broach, J. R. Pringle, and E. W. Jones (ed.), The molecular biology of the yeast Saccharomyces, vol. 1. Cold Spring Harbor Laboratory Press, Cold Spring Harbor, N.Y.

25. Normington, K., K. Kohno, Y. Kozutsumi, M.-J. Gething, and J. Sambrook. 1989. S. cerevisiae encodes an essential protein homologous in sequence and function to mammalian BiP. Cell 57:12231236.

26. Novick, P., S. Ferro, and R. Schekman. 1981. Order of events in the yeast secretory pathway. Cell 25:461-469.

27. Novick, P., C. Field, and R. Schekman. 1980. Identification of 23 complementation groups required for post-translational events in the yeast secretory pathway. Cell 21:205-215.

28. Ossig, R., C. Dascher, H. H. Trepte, H. D. Schmitt, and D. Gallwitz. 1991. The yeast $S L Y$ gene products, suppressors of defects in the essential GTP-binding Ypt1 protein, may act in endoplasmic reticulum-to-Golgi transport. Mol. Cell. Biol. 11: 2980-2993.

29. Riezman, H. 1993. Yeast endocytosis. Trends Cell Biol. 8:273-277.

30. Riles, L., J. E. Dutchik, A. Baktha, B. K. McCauley, E. C. Thayer, M. P. Leckie, V. V. Braden, J. E. Depke, and M. V. Olson. 1993. Physical maps of the six smallest chromosomes of Saccharomyces cerevisiae at a resolution of 2.6 kilobase pairs. Genetics 134:81150.

31. Rosbash, M., P. K. Harris, J. L. Woolford, Jr., and J. L. Teem. 1981. The effect of temperature-sensitive RNA mutants on the transcription products from cloned ribosomal protein genes of yeast. Cell 24:679-686.

32. Rose, M. D., L. M. Misra, and J. P. Vogel. 1989. KAR2, a karyogamy gene, is the yeast homolog of the mammalian $\mathrm{BiP} /$ GRP78 gene. Cell 57:1211-1221.

33. Rose, M. D., P. Novick, J. H. Thomas, D. Botstein, and G. R. Fink. 1987. A Saccharomyces cerevisiae genomic plasmid bank based on a centromere-containing shuttle vector. Gene 60:237-243.

34. Rotenberg, M. O., and J. L. Woolford, Jr. 1986. Tripartite upstream promoter element essential for expression of Saccharomyces cerevisiae ribosomal protein genes. Mol. Cell. Biol. 6:674-687.

35. Rothblatt, J. A., J. D. Raymond, S. L. Sanders, G. Daum, and R. Schekman. 1989. Multiple genes are required for proper insertion of secretory proteins into the endoplasmic reticulum in yeast. J. Cell Biol. 109:2641-2652.

36. Saenz-Robles, M. T., M. Remacha, M. D. Vilella, S. Zinker, and J. P. Ballesta. 1990. The acidic ribosomal proteins as regulators of the eukaryotic ribosomal activity. Biochim. Biophys. Acta 1050: 51-55.

36a.Schekman, R. Personal communication.

37. Schwindinger, W. F., and J. R. Warner. 1987. Transcriptional elements of the yeast ribosomal protein gene $C Y H 2$. J. Biol. Chem. 262:5690-5695. 
38. Shuai, K., and J. R. Warner. 1991. A temperature sensitive mutant of Saccharomyces cerevisiae defective in pre-rRNA processing. Nucleic Acids Res. 19:5059-5064.

39. Stevens, T., B. Esmon, and R. Schekman. 1982. Early stages in the yeast secretory pathway are required for transport of carboxypeptidase $\mathrm{Y}$ to the vacuole. Cell 30:439-448.

40. Udem, S. A., and J. R. Warner. 1972. Ribosomal RNA synthesis in Saccharomyces cerevisiae. J. Mol. Biol. 65:227-242.

41. Vogel, J. P., J. N. Lee, D. R. Kirsch, M. D. Rose, and E. S. Sztul. 1993. Brefeldin A causes a defect in secretion in Saccharomyces cerevisiae. J. Biol. Chem. 268:3040-3043.

42. Waldron, C., and F. Lacroute. 1975. Effect of growth rate on the amounts of ribosomal and transfer ribonucleic acids in yeast. $J$.
Bacteriol. 122:855-865.

43. Warner, J. R. 1991. Labeling of RNA and phosphoproteins in Saccharomyces cerevisiae. Methods Enzymol. 194:423-428.

44. Warner, J. R., and S. A. Udem. 1972. Temperature sensitive mutations affecting ribosome synthesis in Saccharomyces cerevisiae. J. Mol. Biol. 65:243-257.

45. Woudt, L. P., A. B. Smit, W. H. Mager, and R. J. Planta. 1986. Conserved sequence elements upstream of the gene encoding yeast ribosomal protein L25 are involved in transcription activation. EMBO J. 5:1037-1040.

46. Zinker, S., and J. R. Warner. 1976. The ribosomal proteins of Saccharomyces cerevisiae: phosphorylated and exchangeable proteins. J. Biol. Chem. 251:1799-1807. 